\title{
Small States, Islands and Small States that are also Islands
}

\author{
H.W. ARMSTRONG* and R. READ**
}

\begin{abstract}
In recent years there has been considerable research attention directed at understanding the economic performance of sovereign very small states, many of which are also islands. This paper reviews the theoretical and conceptual arguments concerning the different challenges which small states and island economies face within an increasingly globalised system. The empirical evidence drawn from previous research by the authors stands in direct contrast to the theoretical literature. Very small states are shown to have performed generally very well and their economic performance is as good as, and often better, than that of larger states. Interestingly, whether a very small state is an island or not appears to have virtually no influence upon subsequent economic performance. The paper concludes with a comparison of very small states and non-sovereign island economies within Western Europe. Sovereign small states (whether islands or not) generally perform better than their non-sovereign island counterparts in Western Europe. The pattern is not, however, a uniform one. Some non-sovereign islands in Western Europe, particularly those able to develop summer vacation tourism activity have performed well.
\end{abstract}

Key Words: Micro-states, Islands, Economic performance, Discriminant analysis, Censored regression

\section{Introduction}

This paper considers two types of economies which have been rather neglected by researchers in the past: very small states ('micro-states') and islands. Both of these types of economies are extremely common in the global economy, although they are particularly widespread in Sub-Saharan Africa, Europe, the Caribbean and the Pacific. Interestingly many, although not all, of the smallest sovereign states are also islands (or archipelagos).

Previous research by the authors has approached the issue of the determinants of the economic performance of small open economies from the perspective of very small states. Given the large numbers of small states which are also islands, this research has inevitably led to a consideration of the nature of island economies and how 'islandness' can affect the economic performance of small states. This paper seeks to take forward our earlier research exploring the issue of whether islands which are sovereign small states have economic advantages which islands lacking sovereignty do not (i.e. which are regions within large countries). This research is at present focused on Western Europe. In future papers we shall extend the research (as with our earlier work on small states) to wider global data sets. Western Europe has been chosen partly because Europe has many islands as well as

* Department of Geography, The University of Sheffield, Winter Street, Sheffield S10 2TN, United Kingdom (For correspondence and/or offprints).

** Department of Economics, The Management School, Lancaster University, Bailrigg, Lancaster LA1 4YX, United Kingdom. 
small sovereign states. In addition, the European Union's REGIO data base is in the process of being expanded and improved in a manner which will allow much better research on island economies than has been possible in the past.

The paper begins (section 2) with an examination of the main arguments advanced in the past to explain why the economies of islands and small states face distinctive challenges. This is followed in section 3 with a review of the main findings from the authors' earlier published research on the economic performance very small states. Finally, in section 4 evidence from earlier research by the authors on the implications of 'islandness' for the economic performance of very small states is distilled and presented. In addition, results from recent analysis comparing the economic performance of non-sovereign islands and sovereign small states in Western Europe are presented and discussed.

It should be noted that by 'small states' throughout this paper is meant the very smallest states, defined as those with populations under three million persons. There is a vigorous debate in the research literature on what constitutes a 'small state'. The authors, like others researching this field, have been forced by data limitations to resort to population statistics to define the chosen category of very small states. There is a natural break in the distribution of small states by population at around the three million persons mark and this is the sole reason for choosing a three million population threshold. The chosen set of small states should therefore strictly be called 'micro-states' (our own preferred term) or 'mini-states'. If one includes entities. which are not strictly sovereign but which have an unusually high degree of political and economic autonomy (e.g. the Faroe Islands in Denmark and the dependent territories of former colonial powers) there are some 105 'micro-states' across the globe. The dependent territories of former colonial powers (e.g. St Helena) are not strictly sovereign states, but have their own elected political assemblies and also typically have greater economic policy discretion than regions within bigger states.

Other researchers tend to use the term 'mini-state' for entities under five million population. In Europe, opinion has generally settled on calling all states under 10 million population 'small states'. This paper deliberately avoids the debate on what actually constitutes a small state since the paper has another purpose, the examination of the effects of 'islandness'. The authors' preferred definition of 'micro-states' as entities under three million population will therefore be used throughout. Readers interested in the debate on the definition of small states can find summaries of the debate in Armstrong and Read [2], Armstrong et al [6] and elsewhere (e.g. Streeten [34]).

By 'economic performance' in this paper is meant GDP/GNP aggregates and per capita values, growth rates of these and, in some cases, unemployment rates. This is a very limited range of indicators, but in practice the researcher seeking to work at a Western European or global level with islands and micro-states is restricted by severe data problems.

\section{The Economic Performance of Micro-States and Islands : Theoretical Arguments}

Very small states have long been thought to face a distinctive mixture of challenges and opportunities in their attempts to accelerate the pace of economic development. It is for this reason that they have, for many years, been treated in the research literature as a rather unusual set of economic entities. Interestingly, the literature treats islands as facing almost 
identical challenges and opportunities to very small states. This may be partly the result of so many micro-states also being islands (e.g. 72 of the 105 micro-states in our own global data sets are islands or archipelagos). It also, however, almost certainly a reflection of a widespread feeling that islands, as small open economies, face many of the same challenges as micro-states.

Taking the literature on micro-states first, it would be wrong to suppose that microstates are continuously labouring under adverse economic conditions or that they represent a group of states which are failing in some sense. On the contrary, the set of world microstates contains within it some of the most successful and highest per capita income countries of all, such as Iceland and Singapore. In some regions of the world, such as Western Europe, where micro-states are abundant, there is evidence that most micro-states are able to outperform their larger state neighbours (Armstrong and Read [1], [2]). There is clearly every bit as much diversity in the economic performance among micro-states as among large countries.

The relative success of micro-states is borne out by studies of growth rates as well as point-in-time levels of economic performance. These have revealed that country size variables, when incorporated into formal growth models, have virtually no influence on growth rate differentials among countries (Milner and Westaway [28]).

In spite of the evidence of successful economic performance of many of the world's micro-states, it has long been recognised that these states face very serious challenges. Their small size and high degree of openness gives them an unusual degree of exposure to external forces of many kinds. That micro-states are extremely politically and strategically vulnerable has been understood for many years (Harden [21] ; Hintjens and Newitt [22]; Wood [38]). In addition, micro-states must face up to an array of external economic fluctuations which are almost completely outside of their control. Moreover, environmental and topographical factors which may cause sudden and highly disruptive shock effects in a small land area are commonly experienced (Holmes [23]; Bune [14]; Briguglio [12]; Atkins et al [7]). Good examples of this are the periodic devastating effects of hurricanes and volcanic eruptions on Caribbean islands.

Turning to the exclusively economic challenges facing micro-states, a number of different issues have been highlighted. The key problem identified in the research literature for micro-states is the small size of the domestic market. This is seen as being of particular importance in island micro-states or those in the most remote areas of the world such as the Pacific (Knox [24]). Local industrialists have access to domestic demand which allows less than minimum efficient scale (MES) of production, resulting in significantly higher production costs. In addition, $\mathrm{R} \& \mathrm{D}$ is thought to be adversely affected by a small domestic market and this threatens both the development of indigenous technologies and also the emergence of new fast growth high-tech industrial sectors (Kuznets [25]; Thomas [36]; Briguglio $[12])$.

Micro-states which are geographically small face additional challenges arising from their limited natural resource base, often exacerbated by a scarcity of domestic capital. The minority of micro-states which happen to be resource-rich, as would be expected, on the whole perform well. One must be careful however, not to generalise too much from this 
result since some countries with a large natural resource base do not perform well, while others such as Singapore without a resource base can still perform spectacularly well. It should be noted, however, that even those micro-states with a strong natural resource base may nevertheless have an undiversified resource endowment, giving their economies a high degree of over-reliance on a single export-earning source.

It is also sometimes argued that for geographically small micro-states the agricultural sector can absorb such a high proportion of the available land area that alternative activities may be severely constrained (Commonwealth Secretariat [17]). The extent of this problem is not known, especially as it is clear that some micro-states have chosen to simply switch almost completely to imported agricultural products, a process which then allows them to devote their limited land area to higher value-added manufacturing and services. This has allowed states such as Mauritius and Singapore to successfully overcome the problem of a limited land area. What is clear however, is that a limited land area, in combination with a small labour force, means that the standard role of agriculture in the structural transition necessary for industrialisation is limited (but also implies the absence of a large backward agricultural sector). Growth and development in micro-states is therefore more likely to be founded upon investment in human capital, skills and physical capital (Bhaduri et al [11]).

In less developed micro-states, the difficulties encountered in building industries with sufficient employment opportunities has inevitably resulted in out-migration and a reliance on the eventual large inflows of worker remittances. In many cases the economies of microstates which were formerly subsistence-based, or dominated by exports (often to colonial powers) evolved directly into systems characterised by migration, remittances, aid and bureaucracy-the MIRAB economies of Bertram [10]. By contrast, in the successful micro-states, the resulting domestic scarcity of both particular specialist skills and of relatively unskilled labour has been resolved through significant temporary in-migration of labour (often within a framework of carefully managed visa and residence status regulations).

The various constraints on small states, particularly island economies, have forced policymakers there to focus on a narrow array of niche-market products for export. The number of export products will be inevitably very small, as will the number of markets at which these exports can be targeted, both of which enhance the vulnerability of micro-states to exogenous shocks. The small number of export products is the direct result of production capacity constraints and niche market strategies. Export markets tend to be small in number because of limited resources for marketing (by both firms and the government), and also because exports are often channelled via adjacent large states or through the distribution systems of the former colonial powers. This limits access to global markets. Unstable export prices and earnings are a particular problem and 'Dutch Disease' issues are an everpresent threat (MacBean and Nguyen [26]; Corden and Neary [18]). The scope for import substitution is also extremely limited in micro-states since the domestic sector is so small, adding to vulnerability problems.

The extreme openness of small states to both imports and exports tends to greatly restrict the policy options available to their governments. Trade protectionism is generally ruled out because of the adverse impact it would have on the domestic price level and on 
exporters' competitiveness (through higher input prices). Exchange rate variations are rarely successful in such small open economies and are, in any event, frequently not possible where a micro-state either adopts the currency of a larger neighbouring state (e.g. Andorra) or operates a rigidly fixed exchange rate policy with the neighbouring state (e.g. Lesotho). Fiscal policy too tends to be of limited value given the extreme openness of the economy, the low multiplier effects of any spending and the dangers of flight of businesses and residents if taxes are too high. In these circumstances, it is hardly surprising to find that most microstates operate a highly open trading regime.

In addition to the array of economic challenges set out above, which are faced by all micro-states, the literature argues that there are additional problems for islands (sometimes grouped together in the literature with land-locked micro-states). Islands it is alleged, face particularly high transport costs, transport monopoly difficulties, transport reliability issues and diseconomies in loads, routings and return shipments (Brookfield [13] ; Selwyn [33] ; Pant [29] ; Armstrong et al [5]). They must also cope with a heavy dependency upon neighbouring larger states for transport links to export markets. These problems are made much worse where an island is part of an archipelago. How true these arguments are in an era of rapidly falling sea and air transport costs is an issue of some importance which has not yet received the research attention it deserves.

In view of the many challenges discussed above, one may be forgiven for wondering how so many micro-states and islands have been able to prosper. Part of the explanation may lie in the fact that micro-states and islands have for many years simply had no choices. The nature of their situation has meant that they are simply forced to operate within an open, highly competitive trading regime (Streeten [34]). They have not, therefore, fallen into the protectionist trap which has hindered many of their larger state neighbours in the developing world (Chai [15]). Uncompetitive firms simply disappear and only the most successful niche market companies, those able to weather the pressures of competition in export markets, have been able to survive.

Then there is the 'importance of being unimportant', allowing some micro-states and highly autonomous islands within larger sovereign states to develop businesses within a framework of flexible financial, environmental and commercial registration regulations (see Hampton and Abbott [20], and Cobb [16] on offshore financial centres). Larger countries and supra-national entities such as the European Union threaten from time to time to block off the opportunities of micro-states to exploit more flexible regulations (see, for example, The Economist, January 25, 2003 [19] for a recent attempt to close financial services loopholes). Such clampdowns are, however, rare and are in any event usually side-stepped by micro-state governments. Many micro-states and islands too have been able to capitalise on their cultural distinctiveness. This is most clearly seen in those states and islands whose distinctiveness has led to the development of a successful international tourism industry.

Finally, there is a rapidly growing discussion concerning the issue of whether there are advantages in political and economic management associated with being small. On the one hand it can be argued that governments in micro-states can respond quickly to economic change. There may well be great strengths arising from the build-up of social capital within small states and in islands; the networks of trust and norms of reciprocity which are also 
found in some successful sub-national regions-Putnam [30]). On the other hand, the frequency of direct contact between decision-makers and their constituents may encourage nepotism and clientelism. In small states and islands the clash of personalities, combined with limited scope to resolve these clashes, may also make policy-making rather hazardous.

Faced with evidence of the large number of challenges confronting micro-states and islands, those involved in the decolonisation process have frequently asserted that many dependent territories are too small to be viable as independent states. At the height of the decolonisation process this led to pressures to absorb the smaller dependent territories into larger entities or federations prior to independence being granted (Marcy [27] ; Scitovsky [32]). Good examples of this process were St. Kitts \& Nevis, the Malay Federation and the West Indian Federation. This process also led to the very lengthy delays in decolonisation for the very smallest and most remote of the dependent territories (e.g. St. Helena).

The rather pessimistic view in the research literature of micro-states and islands in the 1950s and 1960s has gradually given way to the view that micro-states and islands can often prove to be extremely successful. Many of the micro-states granted independence in the 1950 s and 1960s, for example, have gone on to achieve success and the early pessimistic tone of much of the research literature has now receded.

\section{Empirical Evidence on the Economic Performance of Micro-States}

As noted earlier, previous research by the authors has been based upon information collected for some 105 micro-states, dependent territories of the former colonial powers and highly autonomous regions of some larger countries. The data sets utilised in this previous research were assembled from a variety of sources, particularly the United Nations Statistical Yearbook, World Bank World Development Reports, IMF International Financial Statistics, International Labour Organisation statistics and the Commonwealth Secretariat's Small States: Economic Review and Basic Statistics. In addition, considerable amounts of information were collected directly from the individual states. The most recent work, the results for some of which are reported in this paper, draws upon the EU's REGIO data base.

There are enormous problems involved in seeking to systematically analyse the economic performance of micro-states and island economies :

i. Even the most diligent data collection effort focusing on relatively simple indicators such as GNP per capita face the problem that they inevitably result in truncated data sets. Moreover, these truncated data sets tend to systematically exclude the smaller micro-states and islands-those facing the most severe challenges. There is therefore a danger of introducing systematic bias into any analysis undertaken. Data availability for the very smallest micro-states and islands tends to be either wholly missing or else of poor quality because of inadequately trained and resourced economic statisticians. Widely used data sets at international level such as that of Summers and Heston [35] systematically exclude large numbers of the smallest states. The REGIO data base of the EU tends to group Europe's many smaller islands in with adjacent mainland ('littoral') regions so that they cannot be separately identified. This too causes a truncated data set to result.

ii. The need to produce data sets which are as comprehensive as possible (to lessen the 
problem of truncated data sets) often forces the researcher to deal with information which is unsuitable for the production of continuous data, usually because of lack of harmonisation of statistical information collected by government officials. One way around this problem is to follow the World Bank's lead and develop ordinal or binary data sets. The World Bank, for example, produces estimates of GNP per capita annually for many small states by four categories of GNP per capita (i.e. ordinal data) rather than as a continuous data set.

iii. Frequently it is not possible to develop a data set in which all of the data items represent a single year. Typically one has to be prepared to use data for one year earlier or one year later for some of the micro-states or islands.

These are serious problems and of an order of magnitude greater than that normally faced by the regional scientist. Economic statistics for micro-states and islands are, fortunately, rapidly improving. The European Commission, for example, is actively seeking to develop a new islands data-base and many micro-states have also rapidly improved their economic statistics during the 1990s. In previous research by the authors, the following strategies have been deployed to try to cope with the unusually difficult nature of the data available for micro-states and islands :

i. Information has been collected directly from micro-states where necessary (e.g. where it is unavailable in the large data sets of supra-national bodies such as the IMF).

ii. Checks for robustness of the research results have been undertaken by systematically re-running analyses with alternative data sets where data are more reliable and continuous in nature (even though these inevitably incorporate fewer microstates in total). These cross-checks allow for the robustness of the research results to be ascertained.

iii. Wherever possible, assumptions have been made which are least favourable for the particular hypotheses being tested. In other words, the research has been conducted in a manner which deliberately makes it harder for a given hypothesis to be statistically verified.

iv. Techniques specifically designed for grouped, ordinal and binary data sets have been sought and used. These inevitably lead one into classificatory methods rather than causal analysis (e.g. cluster analysis, discriminant analysis) and into limited dependent variable techniques.

v. The published results have been set out as carefully as possible to expose and take account of biases introduced by data limitations.

One obvious question given the nature of the previous research literature on this subject is whether small size has a detrimental effect on the economic performance of countries. Table 1 suggests that as far as GNP per capita values are concerned it does not. Table 1 compares GNP per capita values (using the World Bank's four-fold categorisation of GNP per capita values) for large states and small states in 2001. Population benchmarks have been used to differentiate three sets of states: those with under three million persons (our own preferred definition of 'micro-states'), those with 3-10 million persons ('small states') and those with over 10 million populations ('large states'). The top part of the table presents 
results for GNP per capita values where the GNP statistics have not been adjusted for purchasing power parities (PPP), while the lower part of the table gives results using PPP adjusted GNP statistics. All figures are in US dollars.

Taking the unadjusted GNP per capita statistics first, Table 1 shows very clearly that there is actually a higher percentage of micro-states in the highest GNP per capita band (39. $4 \%$ ) than for either small states (3-10 million persons-18.3\%) or the large states with over 10 million persons (18.4\%). The reverse is true for the lowest per capita GNP category (which contains $42.1 \%$ of the large states and only $12.7 \%$ of the micro-states). The microstates are found in disproportionately small numbers (compared to all countries taken together) in the lowest two income categories (i.e. under $\$ 745$ and $\$ 746-\$ 2975$ ). They are relatively over-represented in the highest two income categories (i.e. \$2976-\$9204 and over \$9204).

These results are borne out when one examines the PPP adjusted GNP per capita statistics in the lower part of Table 1. PPP adjustments are not available from the World Bank for the full set of 207 countries shown in the top part of Table 1. Indeed, PPP adjusted data are available for only 165 of the 207 countries. As can be seen from the table, PPP adjustment tends also to shift large numbers of countries out of the bottom-most GNP per capita category (under $\$ 745$ ) for the simple reason that the least prosperous countries tend to have the lowest price levels. Nevertheless, it can again be clearly seen that the microstates are disproportionately over-represented in the two highest GNP per capita categories (with $78.7 \%$ of micro-states in these two categories compared with $54.4 \%$ of small states and $62.5 \%$ of the large states). Interestingly, Table 1 also shows that whether a country is an island or not has little effect on economic performance. Islands, as the final two columns of Table 1 show, are over-represented in the highest GNP per capita category and underrepresented in the lowest GNP per capita category.

One problem with this type of direct comparison between micro-states and larger states is that the micro-states are not uniformly distributed around the world. There are disproportionate numbers of micro-states in Western Europe (a prosperous region of the world), and also in the Caribbean, Pacific and Sub-Saharan African regions of the world (less prosperous regions). One rather crude method utilised in previous research by the authors to take account of the regional concentrations of micro-states has been to compare GNP per capita values for micro-states with the weighted average values of GNP per capita for contiguous countries (Armstrong and Read [1] ; Armstrong et al [6]). In Western Europe, all of the micro-states had (utilising 1994 data sets) higher GNP per capita values than the weighted averages of their contiguous neighbours. These results were also robust across both continuous and ordinal data sets and also were found irrespective of whether PPP adjustment was undertaken or not.

Attempts by the authors in their previous research to analyse whether the size of a country influences rates of growth as well as levels of GNP per capita have also suggested that size of state does not seem to be an important determinant. Table 2 presents the results of 'Barro regressions' drawing upon conditional convergence neoclassical growth models. It would, of course, be preferable to run other growth models too (e.g. endogenous growth models or new economic geography models), but adequate data for the appropriate explana- 
Table 1. GNP per capita of micro-states, small states and large states, 2001

A. GNP per Capita, no purchasing power parities adjustment

\begin{tabular}{|c|c|c|c|c|c|c|c|c|c|c|}
\hline & \multicolumn{2}{|c|}{$\begin{array}{l}\text { Micro-states } \\
\text { under } 3 \text { millions }\end{array}$} & \multicolumn{2}{|c|}{$\begin{array}{l}\text { Small states } \\
3-10 \text { millions }\end{array}$} & \multicolumn{2}{|c|}{$\begin{array}{l}\text { Large states } \\
\text { Over } 10 \text { millions }\end{array}$} & \multicolumn{2}{|c|}{ All states } & \multicolumn{2}{|c|}{ Island states } \\
\hline $\begin{array}{l}\text { GNP per } \\
\text { capita }\end{array}$ & Nos. & $\%$ & Nos. & $\%$ & Nos. & $\%$ & Nos. & $\%$ & Nos. & $\%$ \\
\hline $\begin{array}{l}\text { Under } \\
\$ 745\end{array}$ & 9 & 12.7 & 24 & 40.0 & 32 & 42.1 & 65 & 31.4 & 6 & 10.2 \\
\hline $\begin{array}{l}\$ 746- \\
\$ 2,975\end{array}$ & 17 & 23.9 & 13 & 21.7 & 22 & 28.9 & 52 & 25.1 & 15 & 25.4 \\
\hline $\begin{array}{l}\$ 2,976- \\
\$ 9,204\end{array}$ & 17 & 23.9 & 12 & 20.0 & 8 & 10.5 & 37 & 17.9 & 14 & 23.7 \\
\hline $\begin{array}{l}\text { Over } \\
\$ 9,204\end{array}$ & 28 & 39.4 & 11 & 18.3 & 14 & 18.4 & 53 & 25.6 & 24 & 40.7 \\
\hline $\begin{array}{l}\text { All } \\
\text { categories }\end{array}$ & 71 & 100.0 & 60 & 100.0 & 76 & 100.0 & 207 & 100.0 & 59 & 100.0 \\
\hline
\end{tabular}

Source: World Bank, World Development Report 2003, Oxford University Press, Oxford, 2002.

B. GNP per Capita, purchasing power parities adjusted

\begin{tabular}{|c|c|c|c|c|c|c|c|c|c|c|}
\hline & \multicolumn{2}{|c|}{$\begin{array}{c}\text { Micro-states } \\
\text { under } 3 \text { millions }\end{array}$} & \multicolumn{2}{|c|}{$\begin{array}{l}\text { Small states } \\
3-10 \text { millions }\end{array}$} & \multicolumn{2}{|c|}{$\begin{array}{l}\text { Large states } \\
\text { Over } 10 \text { millions }\end{array}$} & \multicolumn{2}{|c|}{ All states } & \multicolumn{2}{|c|}{ Island states } \\
\hline $\begin{array}{l}\text { GNP per } \\
\text { capita }\end{array}$ & Nos. & $\%$ & Nos. & $\%$ & Nos. & $\%$ & Nos. & $\%$ & Nos. & $\%$ \\
\hline $\begin{array}{l}\text { Under } \\
\$ 745\end{array}$ & 1 & 2.1 & 3 & 6.5 & 3 & 4.2 & 7 & 4.2 & 0 & 0.0 \\
\hline $\begin{array}{l}\$ 746- \\
\$ 2,975\end{array}$ & 9 & 19.1 & 18 & 39.1 & 24 & 33.3 & 51 & 30.9 & 8 & 21.1 \\
\hline $\begin{array}{l}\$ 2,976^{-} \\
\$ 9,204\end{array}$ & 21 & 44.7 & 13 & 28.3 & 24 & 33.3 & 58 & 35.2 & 12 & 31.6 \\
\hline $\begin{array}{l}\text { Over } \\
\$ 9,204\end{array}$ & 16 & 34.0 & 12 & 26.1 & 21 & 29.2 & 49 & 29.7 & 18 & 47.4 \\
\hline $\begin{array}{l}\text { All } \\
\text { categories }\end{array}$ & 47 & 100.0 & 46 & 100.0 & 72 & 100.0 & 165 & 100.0 & 38 & 100.0 \\
\hline
\end{tabular}

Source: World Bank, World Development Report 2003, Oxford University Press, Oxford, 2002.

tory variables simply do not exist for most micro-states. As it is, even with 'Barro regressions' such as those shown in Table 2, the simpler versions utilising (global) region dummy variables as proxies for an array of 'conditioning' variables are all that is possible. These are very similar to the types of models run for sub-national regions in the USA, EU and other parts of the world (Barro and Sala-i-Martin [8], [9]). Even so, it is striking in Table 2 that the introduction of a country size variable ('Population') barely improves the fit of the model and the population size variable is also not significant at either the $95 \%$ or $99 \%$ levels. On the other hand, most of the other variables are highly significant. These results bear out the findings of others who have examined the influence of country size on growth (e.g. Milner and Westaway [28]). 
Table 2. Conditional convergence model estimates, 133 countries, GNP per capita growth rates, $1980-93$

\begin{tabular}{|c|c|c|c|c|c|c|}
\hline \multirow[t]{2}{*}{ Variables } & \multicolumn{3}{|c|}{$\begin{array}{l}\text { Equation Excluding } \\
\text { Population Variable }\end{array}$} & \multicolumn{3}{|c|}{$\begin{array}{l}\text { Equation Including } \\
\text { Population Variable }\end{array}$} \\
\hline & Coeff. & t-ratio & Prob & Coeff. & t-ratio & Prob \\
\hline Constant & 0.1344 & 6.62 & 0.000 & 0.1295 & 6.27 & 0.000 \\
\hline GNP per capita, 1980 & 0.0167 & 5.37 & 0.000 & 0.0155 & 4.89 & 0.000 \\
\hline Percentage of GDP, agriculture & -0.0014 & -7.05 & 0.000 & -0.0014 & -6.97 & 0.000 \\
\hline Percentage of GDP, industry & -0.0001 & -0.49 & 0.627 & -0.0002 & -0.74 & 0.460 \\
\hline S. Asia Dummy & 0.0167 & 1.76 & 0.081 & 0.0133 & 1.34 & 0.183 \\
\hline Mid-East/N. Africa Dummy & -0.0022 & -0.26 & 0.799 & -0.0028 & -0.32 & 0.750 \\
\hline East Europe/C. Asia Dummy & -0.0009 & 0.14 & 0.889 & -0.0004 & 0.05 & 0.956 \\
\hline Latin Am/Caribbean Dummy & -0.0007 & 0.12 & 0.902 & -0.0001 & 0.02 & 0.983 \\
\hline East Asia/Pacific Dummy & 0.0304 & 4.49 & 0.000 & 0.0281 & 4.02 & 0.000 \\
\hline Western Europe Dummy & 0.0364 & 4.26 & 0.000 & 0.0342 & 3.92 & 0.000 \\
\hline N. America Dummy & 0.0305 & 1.92 & 0.057 & 0.0257 & 1.57 & 0.118 \\
\hline Population 1993 & - & - & - & 0.000 & 1.24 & 0.218 \\
\hline Estimate rate of beta convergence & \multicolumn{3}{|c|}{$1.67 \%$} & \multicolumn{3}{|c|}{$1.55 \%$} \\
\hline Diagdostics & \multirow{2}{*}{\multicolumn{3}{|c|}{0.51}} & \multirow{2}{*}{\multicolumn{3}{|c|}{0.52}} \\
\hline $\mathrm{R}^{2}$ & & & & & & \\
\hline DW & \multicolumn{3}{|l|}{1.93} & \multicolumn{3}{|l|}{1.97} \\
\hline SER & \multicolumn{3}{|l|}{0.0195} & \multicolumn{3}{|l|}{0.0195} \\
\hline $\mathrm{SC}$ & \multicolumn{3}{|l|}{0.1457} & \multicolumn{3}{|l|}{0.0214} \\
\hline HT & \multicolumn{3}{|l|}{0.5607} & \multicolumn{3}{|l|}{0.2028} \\
\hline
\end{tabular}

Notes: 1. Equations are fitted for 133 countries with the average annual growth rate of GNP per capita for the 13 years from 1980-1993 as the dependent variable. Nonlinear least squares utilised.

2. SER is the standard error of the regression. SC gives the results of Lagrange multiplier tests for first-order serial correlation. HT gives the results of heteroskedasticity tests based on the regression of squared residuals on squared fitted values. The critical values for $\chi^{2}(1)$ for these tests are 2.71 and 3.84 at the 0.10 and 0.05 levels respectively.

3. The estimated rate of beta convergence is derived from the partical regression coefficoent on the GNP per capita, 1980 variable. It is expressed as a percentage rate of convergence per annum.

Source: Armstrong et al [6], Table 1.

\section{Is There a Separate Role for 'Islandness' in Influencing the Economic Performance of Micro-States?}

Research on the determinants of the wide differences in economic performance which exist between different individual micro-states (which are actually wider than between the large states), and in particular between those which are islands and those which are not, is hampered by the lack of clear theoretical models. As section 2 has shown, there is a large literature on possible determinants of the economic performance of micro-states and island economies, but precious little consensus or formal theorising. Research is also seriously hampered by the lack of harmonised statistics for most of the possible explanatory variables one would wish to use. 
The approach adopted in previous research by the authors has involved developing a range of variables which attempt to examine the role of the following on micro-state GNP per capita :

- Industrial structure. One of the most persistent themes in the existing theoretical and conceptual literature on micro-states is that as extremely open economies with tightly constrained indigenous resources (labour, land etc.) they are forced to develop niche market industries which must compete globally (or at least within their local global region such as Europe). They are helped in this task by 'the importance of being unimportant' - their ability to tailor legal, fiscal and other regulations to attract and develop niche sectors (e.g. offshore finance). In previous research the authors have developed binary and ordinal measures of the sectoral industrial specialisation of different micro-states. The explanatory variables developed by the authors encompass the agricultural sector (AGRIC), tourism (TOURISM), financial services (FINAN) and manufacturing (MANFG). The precise definitions of these variables are discussed in Annex 1. An unfortunate feature of these variables if that the available data simply do not allow the precise niche markets specialised in by a micro-state to be identified. It would be particularly useful, for example, to know whether a microstate specialising in tourism is specialised on cruise tourism, package holiday tourism, or cultural tourism etc. Similar comments apply to manufacturing, the finance sector and agriculture. To date, it has not been possible (because of data availability. problems) to define such concise explanatory variables picking up niche market specialisation.

- Resource endowment. Some micro-states are fortunate in having valuable resource endowments (e.g. oil, fish stocks). A simple RESOUR dummy variable is used to identify such states in the models fitted.

- Global region. Most micro-states are extremely open, trading economies. They are, however, typically heavily dependent on trade with, and through nearby larger states. For those micro-states where good trade statistics exist, it is also clear that they are rarely fully globalised. They tend instead to have much closer links with other countries within their own particular global region than the wider world economy (i.e. they are 'regionalised' rather than truly 'globalised' economies). The economic performance of a micro-state is therefore likely to crucially depend on how well or badly the region of which it is a part is doing. Hence in previous research the authors have constructed an ordinal explanatory variable (REGION) which attempts to allow for this likely determinant of economic performance. This variable too is discussed in more detail in Annex 1.

- Sovereignty. Since the data sets used in previous research by the authors include dependent territories of the former colonial powers as well as some highly autonomous regions of larger countries, a simple binary explanatory variable has been developed to differentiate sovereign micro-states (using the UN definition of political sovereignty) from dependent states and regions (SOVRT-see Annex 1).

- Overseas aid. Many developing micro-states are in receipt of significant overseas aid flows. So too are the dependent territories and highly autonomous regions. In 
previous research, the authors have developed and utilised an explanatory variable (ODAPC) which attempts to allow for the effect of these fiscal transfers (see Annex 1).

- Islandness. Finally, and of particular importance to this paper, in previous research the authors have incorporated a simple binary explanatory variable indicting whether the micro-state is an island or archipelago (ISLAND).

Table 3 summarises the results of earlier research by the authors for explanatory models which incorporate all of the above variables, including ISLAND. Table 3 gives a summary of the results of discriminant analysis and regression analysis (utilising a censored regression approach). In both cases the dependent variable is the World Bank's four-fold grouping of GNP per capita for micro-states and dependent territories. This is the grouping variable in the discriminant analysis and forms the dependent variable in the censored (grouped) regression.

A conventional step-wise Wilks' lambda algorithm was used in the discriminant analysis, the results of which are set out in the first two columns of Table 3 . This selects the independent variables in order of importance in the final discriminant classification. The order in which the variables have entered the analysis (and hence their relative importance) is given in parentheses in column 3 of the table (the column marked 'Fit of the model-Wilks' lambda'). Where a variable fails to meet a minimum F-to-enter criterion it is excluded from the analysis (shown by the word 'Excluded' at appropriate points in the second and third columns of Table 3). The standardised canonical discriminant coefficients in the second column of Table 3 (the column marked 'Standardised canonical discriminant coefficents') are the $b$ coefficients in the discriminant function (similar to partial regression coefficients). The 'Fit of model-Wilks' lambda' coefficients in the third column of Table 3 show the significance of each variable in the final discriminant function. The various diagnostics in the bottom part of the first column of the table show the overall degree of fit of the discriminant classification.

The results of the discriminant analysis are generally very good. The overall canonical correlation value is 0.81 and the eigenvalue, chi-square and Wilks' lambda tests all suggest that the variables utilised give a good classification of micro-states into the four GNP per capita groups.

Turning to the influence of individual variables, the standardised canonical discriminant coefficients shown in the top portion of the first column of Table 3 reveal a distinctive set of relationships. The REGION variable has a positive relationship with GNP per capita and this variable enters the function at the third round of the step-wise process, indicating that it plays a strong role in the classification process. This shows that the region of the world in which a micro-state or dependent territory is located has a major influence on its GNP per capita. The TOURISM variable is also both an important one and has a strong positive relationship with GNP per capita. So too is AGRIC, although the relationship here is strongly negative. RESOUR and FINAN also play important roles (in a positive manner) in the analysis. The MANFG variable, however, is excluded from the analysis and does not appear to have any significant effect on GNP per capita. The SOVRT variable has a negative sign. That is, even in a function in which an array of other key variables known to affect micro-state GNP per capita are included, the role of sovereignty appears to remain a 
Table 3. Results of discriminant and censored regression analysis of the differential economic performance of micro-states GNP per capita, 1994

Discriminant analysis, $1994 \quad$ Censored (grouped) regression, 1994

\begin{tabular}{|c|c|c|c|c|c|c|}
\hline \multirow{2}{*}{ Explanatory variables } & \multirow{2}{*}{$\begin{array}{c}\text { Standardised } \\
\text { canonical } \\
\text { discriminant } \\
\text { coefficients }\end{array}$} & \multirow{2}{*}{$\begin{array}{l}\text { Fit of model- } \\
\text { Wilks' lambda }\end{array}$} & \multicolumn{2}{|c|}{ Model 1} & \multicolumn{2}{|c|}{ Model 2} \\
\hline & & & Coeff. & $t$ & Coeff. & $t$ \\
\hline CONSTANT & - & - & $3,083.2$ & $2.43^{*}$ & $2,131.0$ & 1.68 \\
\hline REGION & 0.26286 & 0.41058 & 393.7 & $1.97^{*}$ & 427.0 & $2.07^{*}$ \\
\hline ISLAND & -0.05292 & $0.29493(5)$ & $-1,200.5$ & -1.45 & 195.3 & 0.24 \\
\hline TOURISM & 0.61704 & 0.62081 (1) & $2,056.2$ & $4.32^{* *}$ & $1,873.6$ & $4.15^{* *}$ \\
\hline AGRIC & -0.56475 & $0.50470(2)$ & $-2,981.9$ & $-3.74^{* *}$ & $-2,890.7$ & $-3.66^{* *}$ \\
\hline RESOUR & 0.58258 & 0.34905 (4) & $3,420.8$ & $3.89^{* *}$ & 3328.7 & $3.97^{* *}$ \\
\hline FINAN & 0.24905 & $0.22873(7)$ & $2,545.8$ & $2.95^{* *}$ & $1,675.8$ & $2.20 * *$ \\
\hline MANFG & Excluded & Excluded & -563.2 & -0.62 & 36.98 & 0.05 \\
\hline SOVRT & -0.44138 & $0.26192(6)$ & $-2,308.8$ & $-3.04^{* *}$ & $-2,405.8$ & $-3.12^{* *}$ \\
\hline ODAPC & - & - & - & & -0.22 & -1.20 \\
\hline Eigenvalue & 1.8813 & & $\begin{array}{r}\text { Log-like } \\
105\end{array}$ & $\begin{array}{l}\text { lihood }= \\
667\end{array}$ & $\begin{array}{r}\text { Log-like } \\
66 .\end{array}$ & $\begin{array}{l}\text { lihood }= \\
551\end{array}$ \\
\hline $\begin{array}{l}\text { Canonical correlation } \\
\text { coefficient }\end{array}$ & 0.81 & & $n=$ & 80 & $n=$ & 76 \\
\hline
\end{tabular}

\begin{tabular}{|l|c|}
\hline Chi-square & $\begin{array}{c}41.069 \\
(p=0.000)\end{array}$ \\
\hline Wilks' lambda & 0.66 \\
\hline Classification success : & $73.3 \%$ \\
\cline { 1 - 1 } -Overall & $92.3 \%$ \\
\cline { 1 - 1 } $\begin{array}{l}\text {-Lower GNP per capita } \\
\text { group }\end{array}$ & $70.6 \%$ \\
\cline { 1 - 1 } $\begin{array}{l}\text {-Lower-middle GNP per } \\
\text { capita group }\end{array}$ & $70.0 \%$ \\
\cline { 1 - 1 } - Upper-middle GNP per \\
capita group
\end{tabular}

Notes:

1. The discrimiant analyses were undertaken using the stepwise Wilks' lambda method: to a maximum of three functions, results being shown for function 1 (accounting for $80.3 \%$ of the variance). Variables entering the function must satisfy tolerance level and F-to-enter criteria, where the maximum tolerence level is 0.001 and the minimum F-to-enter criterion is 1.00 The selection rule is to maximise Wilks' lambda. Variables which fail the F-to-enter criterion and are therefore left out of the final functuin are marked in the tables as 'excluded'. Standardised canonical dicriminant coefficients are similar, but not identical to regression coefficients. Eigenvalues measure the ratio of the between-group sums of squares to the total sum of squares. Large eigenvalues therefore indicate a 'good' discriminant function. In a two-group case, the canonical correlation is equivalent to the value of the Pearson correlation coefficient between the discriminant score and the binary group variable. A value close to 1.00 is therefore to be preferred. The chi-square test is derived from Wilk's lambda and tests for the significance (shown in parenthesis in the table) of differences between group means.

2. The censored (grouped) regressions have been estimated using the LIMDEP software package, using maximum likelihood procedures. Limits to the groups in these regressions are those of the World Bank's GNP per capita classes - the dependent variable (i.e. under $\$ 725, \$ 726-\$ 2,895, \$ 2,896$ $\$ 8,955$ and Over $\$ 8,955)$. A single asterisk denotes $95 \%$ significance and a double asterisk $99 \%$ significance.

3. For the censored (groups) regressions (columns 5 and 6 ) it should be noted that while Model 1 was run with a data set of 80 states, data restrictions associated with the ODAPC variable meant that the data set for Model 2 comprise only 76 states.

Source: Armstrong and Read [3], Tables 2-4. 
negative one. Dependent territories appear, other things equal, to enjoy higher GNP per capita values than their sovereign micro-state counterparts (although it must be borne in mind, as Table 1 has shown, that sovereign micro-states and dependent territories as a group perform better than their larger country counterparts).

Turning to the particular focus of this paper, the role of 'islandness' in determining the economic performance of micro-states, the ISLAND variable has the expected negative coefficient. However, it enters the discriminant function only at a late stage (fifth out of the seven variables) and therefore has only a weak influence.

While discriminant analysis is a useful exploratory tool, as a classification technique it lacks the explanatory power of regression analysis. The grouped nature, however, of the World Bank's classification of states by GNP per capita, makes causal analysis a difficult task. Since the dependent variable is available as the World Bank's four per capita GNP classes, a censored regression model can be used. Of the range of limited dependent variable models, grouped data regression is the appropriate approach. Table 3 gives the results of two censored (grouped) regression models, the first excluding ODAPC (see column 4 marked 'Model 1') and the second including ODAPC (see column 5 marked 'Model 2'). The dependent variable in both models is GNP per capita while the independent variables are those discussed earlier. In each run of the model, the column headed 'Coeff' gives the partial regression coefficients, while ' $t$ ' is the asymptotic t-ratio.

Although some caution should be exercised in comparing the Model 1 and Model 2 results (because different sized data sets are used in each), Table 3 once again indicates that the global region within which the micro-state or dependent territory is located (REGION) is of significance, as is the ability of the state to develop tourism, financial services and/or a strong resource-exploiting economic base (TOURISM, FINAN and RESOUR). By contrast, a large agricultural sector (AGRIC) is again a clear handicap. All of these explanatory variables are significant at the $95 \%$ and $99 \%$ levels. MANFG as in the discriminant analysis is a weak explanatory variable. The ISLAND variable performs poorly in both Model 1 and Model 2. In Model 1 the ISLAND variable has the expected negative sign on its partial regression coefficient, but the variable is not significant at either the $95 \%$ or $99 \%$ level. In Model 2 the variable is again insignificant and this time it has a positive coefficient. Turning to the role of sovereignty as an explanatory variable (SOVRT), Table 3 reveals that this variable has a significant (at 95\% and 99\% level) negative relationship with GNP per capita; the dependent territories appear to have higher GNP per capita values than their sovereign counterparts. This is an unexpected result since it suggests that sovereign micro-states (other things equal) tend to do less well than those which are still dependent territories. Moreover, this is not the result of higher foreign aid flows to the dependent territories (ODAPC in Table 3, which is insignificant).

In summary, both the discriminant analysis and censored regression analysis indicate that 'islandness' has little or no significance in explaining differences between micro-states in GNP per capita levels in the global economy. Moreover, this is the case despite the microstates data sets having included large numbers of some of the most geographically isolated island micro-states and dependent territories on the planet, including many Pacific microstates. This is an unexpected finding since as the review of the literature in section 2 has 
indicated, in the opinion of many previous researchers that (a) islands share virtually all of the problems and challenges faced by sovereign micro-states, and (b) islands have some additional problems as well (especially related to transport issues). Our own research on micro-states clearly indicates that the traditional rather pessimistic view of the economic challenges facing facing islands may be wrong. The particular problems associated with transport costs and other aspects of transport links for islands (e.g. reliability, the unbalanced nature of on- and off-island freight flows etc.) are beginning to be challenged. There is evidence in Europe, some undertaken by the authors (Armstrong et al [5]) that transport barriers may well have been exaggerated in the research literature. Moreover, transport costs per unit of output have been falling consistently at a global scale for many years (through a combination of transport infrastructure improvements, economies of scale and innovation in both transport and within manufacturing itself which have cut transport costs). Other variables such as REGION and the sectoral specialisation variables such as TOURISM, RESOUR and FINAN are much more important than the ISLAND variable.

One possible explanation of the unexpectedly results on the role of 'islandness' is that our data sets have until now only included micro-states. It is therefore quite possible that the advantages of being a sovereign state (or a dependent territory of sub-nation region with an unusually high degree of autonomy) outweigh the disadvantages associated with being an island. This is certainly logical, although it does suggest that the advantages of being a sovereign micro-state must be very powerful indeed to overcome the alleged disadvantages of such remote islands as are to be found in our data sets.

The limitations of our micro-states data sets for examining the independent role of 'islandness' have led us in our more recent research to attempt to seek better tests of the role of 'islandness'. Within Western Europe, the EU's REGIO data base is beginning to open up some interesting options for researchers interested in islands. The existing $\mathrm{EU}$ of 15 member states contains within it many hundreds of islands. These islands range greatly in both remoteness and size (from Sicily in Italy with a population of 5.1 million persons down to uninhabited islands-treating the island of Great Britain as part of the mainland of Europe). In addition, Western Europe contains a number of micro-states and highly autonomous regions - there are 15 such entities from Western Europe in our micro-states data set.

Figures 1 and 2 present preliminary findings from our recent research on the economic performance of islands within Western Europe. These graphs draw upon GDP per capita and unemployment rate data from the REGIO data base for Western Europe. GDP per capita values and unemployment rates are, of course, only two of many potential indicators of economic performance that could be used. In practice, however, researchers are extremely limited in terms of the indicators for which reliable statistics exist for micro-states. GDP per capita and unemployment rates represent the two most widely available statistics and also have the advantage of being widely used and understood measures of economic performance. It should also be noted that GDP per capita values and unemployment rates do throw light on rather different aspects of economic performance. They are not mere substitutes for one another. This is clearly shown if correlation coefficients are estimated between GDP per capita and unemployment rates. Although in both cases (GDP per capita and GDP per capita at PPP - see Figures 1 and 2) the correlation coefficients are negative (i. 


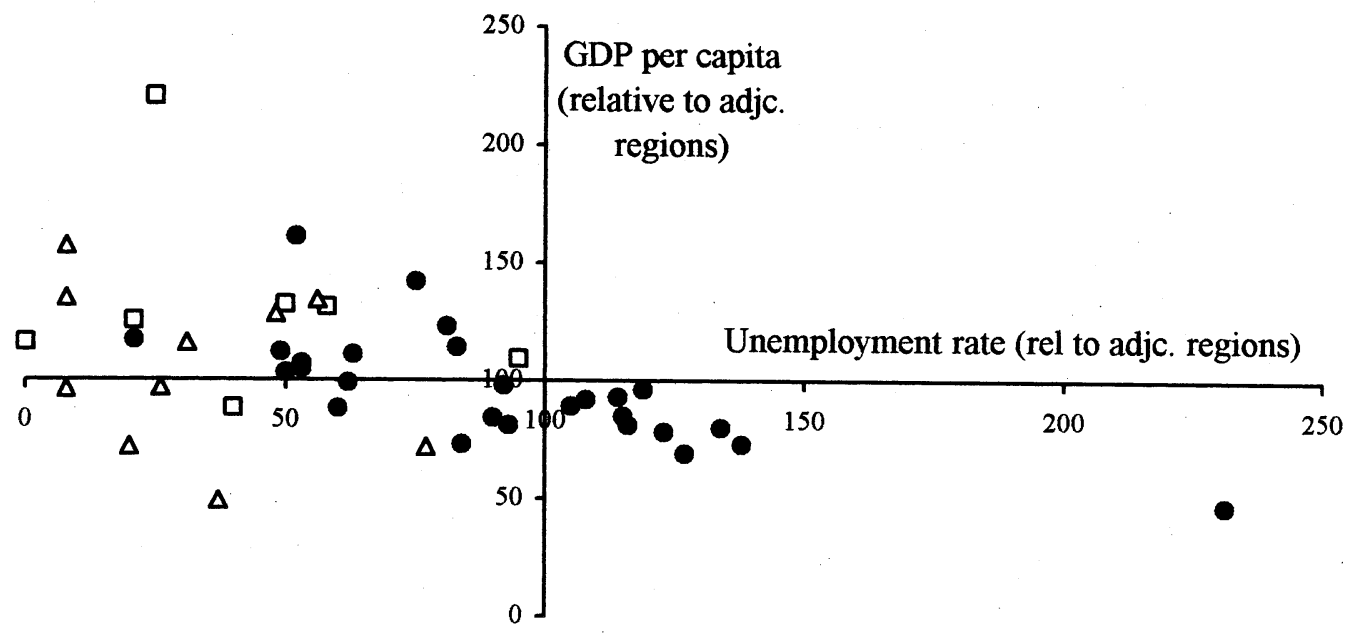

\section{- Islands $\square$ Sov Not Isl $\Delta$ Sov Island}

Figure 1. GDP per capita and unemployment rates relative to adjacent regions, 1999 (not PPP adjusted)

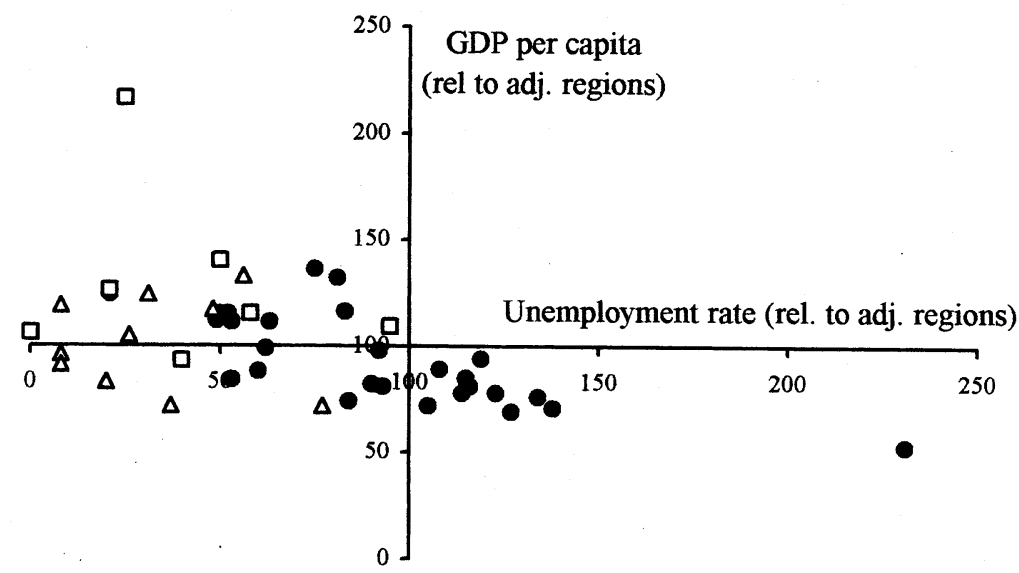

\section{- Islands $\square$ Sov Not Isl $\Delta$ Sov Island}

Figure 2. GDP per capita and unemployment rates relative to adjacent regions, 1999 (at PPP)

e. indicating that islands and micro-states with high unemployment also tend to have low GDP per capita levels), the correlation coefficients are only - 0.533 for GDP per capita against unemployment (Figure 1) and -0.531 (GDP per capita at PPP against unemployment). That is, these two variables are by no means perfectly correlated.

The REGIO data have been extended to incorporate data for the micro-states (most of 
which are not EU members) within Western Europe. Unfortunately, the boundaries of the NUTS2 and NUTS3 regions of the REGIO data base allow only a minority of Western European islands to be analysed alongside the micro-states. Figures 1 and 2 therefore represent truncated data sets which comprise only $27 \mathrm{EU}$ islands, plus a further 10 sovereign micro-states and highly autonomous regions which are also islands. The islands included are the larger ones within the EU and it is the many smaller EU islands which are excluded. Until better data become available to allow analysis of the economic performance of the smaller islands, the biases introduced by the truncated nature of the REGIO data are not known. Figures 1 and 2 show GDP per capita values and unemployment rates for the following entities:

1. Islands (and archipelagos) within EU member states. Useable data were obtained for 27 such entities: Sjaelland (Denmark), Bornholm (Denmark), Fyn (Denmark), Rugen (Germany), Zakinthos (Greece), Kerkyra (Greece), Kefallinia (Greece), Lefkada (Greece), Evvoia (Greece), Lesvos (Greece), Samos (Greece), Dodekannisos (Greece), Kyklades (Greece), Kriti (Greece), Baleares (Spain), Corse (France), Ireland, Sicilia (Italy), Sardegna (Italy), Aland (Finland), Gotland Sweden), Isle of Wight (UK), Anglesey (UK), Northern Ireland (UK), Western Isles (UK), Orkeney Islands (UK), and the Shetland Islands (UK).

2. Sovereign Micro-States and Highly Autonomous Regions: Those Which Are Islands

Acores, Canarias, Iceland, Cyprus, Faroe Islands, Guernsey, Jersey, Isle of Man, Madeira and Malta.

3. Sovereign Micro-States and Highly Autonomous Regions: Those Which Are Not Islands

Andorra, Ceuta \& Melilla, Liechtenstein, Luxembourg, Monaco, San Marino, and Gibraltar.

Figures 1 and 2 utilise GDP per capita data (in Euros) and unemployment rates for various Western European islands and micro-states for the year 1999 (the latest available year for comparable statistics). In Figure 1 the GDP per capita statistics have not been adjusted for purchasing power parities, while in Figure 2 they have (using the EU's purchasing power standard system-PPS). In each of the two graphs, the GDP per capita values and unemployment rates of each island and micro-state have been expressed as a percentage of the (population) weighted average for the adjacent NUTS2 level regions of the EU. Figures greater than 100 therefore show that the GDP per capita or unemployment rate is greater than the average value for surrounding EU regions. Figures under 100 show situations where the islands or micro-states have values below those of the adjacent regions. By 'adjacent' regions for micro-states which are not islands is meant regions which share a common boundary (i.e. are contiguous) with the micro-state. For the islands, by 'adjacent' is meant the closest landfall European regions in a 360 degree arc around the island. For adjacent EU regions NUTS2 rather than NUTS3 regions were used. This is because the GDP per capita values for the larger NUTS2 regions are more reliable than values for the much smaller NUTS3 regions.

In Figures 1 and 2 the three sets of entities identified earlier are shown: islands which are ordinary regions within larger EU member states ('Islands'), sovereign micro-states which are islands ('Sov. Island'), and sovereign micro-states which are not islands ('Sov. Not Isl.'). 
The 'Islands' entities are identified as solid black circles on the graphs, while the 'Sovereign Islands' are shown as crosses, and the 'Sovereign Not Islands' are shown as triangles.

Figures 1 and 2 give very similar results, showing that PPP adjustment of the GDP per capita values does not greatly affect the overall results. In both graphs no fewer than 11 of the 17 micro-states and highly autonomous regions are in the top left quadrant, indicating that they have higher GDP per capita values and lower unemployment rates than adjacent EU regions. The remaining 6 micro-states and highly autonomous regions have lower GDP per capita values than contiguous regions, but also lower unemployment rates. Most telling of all is the fact that none of the micro-states and highly autonomous regions have either GDP per capita values lower than, or unemployment rates higher than their adjacent region neighbours (i.e. the bottom right quadrant).

Turning to the 'Islands' group (i.e. those lacking sovereignty or any large degree of autonomy within the larger EU countries), a more mixed picture emerges. No fewer than 11 of the 27 'Islands' have both lower GDP per capita values and higher unemployment rates than their adjacent EU regional counterparts (i.e. are in the bottom right quadrant). A further 7 of the 27 islands have relatively low unemployment rates ( 6 where unadjusted GDP data are used-Figure 1), but also low GDP per capita values (i.e. the bottom left quadrant). However, there are still 9 'Islands' which share with the micro-states the advantage of both higher GDP per capita and lower unemployment rates than their adjacent region counterparts (i.e. the top left quadrant).

Three main conclusions would seem to flow from the evidence in Figures 1 and 2 :

- Within Europe, being a sovereign micro-state or a highly autonomous region does seem to confer economic advantages (by comparison with the adjacent regions of larger countries) reflected in relatively high GDP per capita and/or relatively low unemployment rates.

- 'Islandness' seems to be a necessary, but not sufficient condition for poor economic performance (relative to adjacent, mainly mainland EU regions). While many EU islands lacking autonomy or sovereignty (11 out of 27) are indeed in the bottom right quadrant (indicating a relatively poor performance on both GDP per capita and unemployment rates), there are also significant numbers in both the top left and bottom left quadrants. Interestingly, virtually all of those in the top left quadrant (i.e. 'good performers') are in the Mediterranean areas of the EU (especially Greece and Spain) where they benefit from a particular niche-market specialisation as a result of their favourable climate and geographical location, namely package summer tourism.

\section{Conclusion}

This paper has examined the economic performance of global micro-states and has also presented some recent evidence on the economic performance of a number of EU island economies (for which data are available for 1999 from the REGIO data base). A number of conclusions would appear to be valid.

Firstly, at a global level, the majority of micro-states (under 3 million population) appear to exhibit strong economic performance. There is no evidence that being a very small state is systematically a barrier to fast growth or high GNP per capita levels. On the 
contrary, many micro-states can be shown to perform exceptionally well. Indeed, when the particular global region within which the micro-state is located is allowed for, the vast majority of micro-states perform better than neighbouring states.

Secondly, there is evidence that niche market specialisation is important in explaining the economic performance of micro-states, with tourism, financial sector and resource endowments being particularly important.

Thirdly, early results of research by the authors for Western Europe, in which a comparison has been made between sovereign island micro-states and islands which lack sovereignty (i.e. are simply normal regions within bigger EU states) suggests :

a) Sovereignty and greater autonomy does seem to confer significant additional benefits over non-sovereignty. Island micro-states do well on the whole.

b) 'Islandness', however, does seem on balance to be something of a handicap for EU regions which lack sovereignty. However :

c) The results are far from unambiguous for there are wide variations in performance between different non-sovereign EU island regions. Interestingly, those that do well seem to have managed to develop a niche market strategy related to tourism. 'Islandness' does not therefore necessarily seem to result in poor economic performance within Western Europe.

The EU islands research reported here is still very much in its infancy. The REGIO data set is highly truncated-most of the smaller islands are omitted because of data problems. Hopefully this situation will be rectified and it will then be possible to look for the possible effects of the size of each island on economic performance A priori, one would expect the smaller islands to suffer the greatest problems.

The use of EU REGIO data sets offers the potential to extend the analysis to look at the effects of remoteness form the EU market on islands (through excellent accessibility indices which now exist for EU regions), as well as a variety of other explanatory variables for endogenous growth models and the like. It would also be valuable to define 'sovereignty' much more carefully, perhaps distinguishing between political and economic sovereignty, and various aspects of both of these. The authors also intend to take advantage of data improvements to develop global data sets for more recent years for micro-states. It may be possible to develop integrated island and micro-state data sets for other regions of the world. We are also exploring how the policy successes of micro-states may yield lessons which policymakers in regions being granted greater autonomy and regionally devolved elected assemblies might profitably learn from (Armstrong and Read [4]).

There is a pressing need to take forward research on why it is that so many micro-states perform well within the modern global economy and also why being an island does not seem to be the handicap to economic performance that one would intuitively expect. Our own research suggests that the development of niche markets and other strategies play a role in allowing micro-states to prosper despite the challenges they face. It is, however, important that additional research be undertaken on various other possible determinants of the economic performance of islands and micro-states which have not been included within our own research models. It is possible, for example, that the governance arrangements and political structures of micro-states and islands may play an important role, particularly given the need 
of many of these entities to respond quickly and flexibly to exogenous changes. The nature and role of the social capital of micro-states and island communities is another area where research is likely to prove profitable. We are also grateful to one of the referees of this paper for pointing out that the models we have employed essentially only consider the role of geography in terms of the location of a micro-state or island with respect to the outside world. To date, our research has not considered the role of the internal geography of these entities, for example on how high population density, urbanised micro-states may enjoy agglomeration economies not available to other less urbanised states. Indeed, the application of new economic geography (NEG) models to micro-state and island economies would be a welcome extension of research on this group of fascinating, but still very poorly understood, entities within the global economic system.

\section{Acknowledgements}

The research reported in this paper is based in part upon statistical material collected as part of a project funded by the UK Department for International Development (formerly the Overseas Development Administration: ODA grant R6622: The Economic Performance of Micro-States-H.W. Armstrong, R.J. de Kervenoael, X. Li and R. Read, The Economic Performance of Micro-States, Report for the Overseas Development Administration (London : Overseas Development Administration, 1996). The UK Department for International Development (DFID) supports policies, programmes and projects to promote international development. DFID provided funding for this study as part of that objective but the views and opinions expressed are those of the authors alone. The authors would also like to acknowledge participants at the Pacific Regional Science Conference Organisation Secretariat Symposium at Hokkaido, Japan on 4-7 October 2002 for helpful comments and suggestions, particularly Isao Hara, Yoshiro Higano, Peter Nijkamp and Jacques Poot. In addition, the comments and suggestions of the two (anonymous) referees have proved to be extremely helpful. The authors remain, of course, responsible for any remaining errors or misunderstandings.

\section{References}

[1] Armstrong, H.W., and Read, R., 1994, Micro-states, autonomous regions and the European Union, European Urban and Regional Studies, vol. 1, 71-78.

[2 ] Armstrong, H.W., and Read, R., 1995, Western European micro-states and EU autonomous regions: The advantages of size and sovereignty, World Development, vol. 23, 1229-1245.

[ 3 ] Armstrong, H.W., and Read, R., 2000, Comparing the economic performance of dependent territories and sovereign micro-states, Economic Development and Cultural Change, vol. 48, 285-306.

[4 ] Armstrong, H.W., and Read, R., 2003, Micro-states and sub-national regions: Mutual industrial policy lessons, International Regional Science Review, vol. 26, 117-141.

[5 ] Armstrong, H.W., Johnes, G., Johnes, J., and MacBean, A.I., 1993, The role of transport costs as a determinant of price level variations between the Isle of Man and the United Kingdom, World Development, vol. 21, 311-318.

[6] Armstrong, H.W., de Kervenoael, R.J., Li, X., and Read, R., 1998, A comparison of the economic performance of different micro-states and between micro-states and larger countries, World Development, vol. 26, 639-656. 
[ 7 ] Atkins, J.P., Mazzi, S., and Easter, C.D., 2000, A Commonwealth Vulnerability Index for Developing Countries: The Position of Small States, Commonwealth Economic Paper Number 40, London, Commonwealth Institute.

[ 8 ] Barro, R., and Sala-i-Martin, X., 1992, Convergence, Journal of Political Economy, vol. 100, 223251.

[9] Barro, R., and Sala-i-Martin, X., 1995, Economic Growth, Boston, McGraw-Hill.

[10] Bertram, G., 1986, 'Sustainable development' in Pacific micro-economies, World Development, vol. 14, 809-822.

[11] Bhaduri, A., Mukherji, A., and Sengupta, R., 1982, Problems of long term growth in small economies: A theoretical analysis, in B. Jalan (ed), Problems and Policies in Small Economies, London, Croom Helm, 49-68.

[12] Briguglio, L., 1995, Small island developing states and their economic vulnerabilities, World Development, vol. 23, 1615-1632.

[13] Brookfield, H.C., 1973, Multum in parvo: Questions about the diversity and diversification in small developing countries, in P. Selwyn (ed), Development Policy in Small Developing Countries, London, Croom Helm, 54-76.

[14] Bune, P., 1987, Vulnerability, The Courier, vol. 4, 85-87.

[15] Chai, S-K., 1998, Endogenous ideology formation and economic policy in former colonies, Economic Development and Cultural Change, vol. 46, 263-290.

[16] Cobb, S.C., 2001, Globalization in a small island context: Creating and marketing competitive advantage for offshore financial centres, Geografiska Annaler, vol. 83B, 161-174.

[17] Commonwealth Secretariat, 1996, Small States : Economic Review and Statistics : Annual Series, 2, London, Commonwealth Secretariat.

[18] Corden, W.M., and Neary, P., 1982, Booming sectors and deindustrialisation in small open economies, Economic Journal, vol. 92, 825-848.

[19] The Economist, 2003, The taxman cometh, January 25, p. 82.

[20] Hampton, M., and Abbott, J.S., 1999, Offshore Finance Centres and Tax Havens: The Rise of Global Capitalism, Indiana, Ichor Business Books.

[21] Harden, S., 1985, Small is Dangerous: Micro States in a Macro World, London, Pinter.

[22] Hintjens, H.M., and Newitt, M.D.D., 1992, The Political Economy of Small Tropical Islands: The Importance of Being Small, Exeter, University of Exeter Press.

[23] Holmes, F., 1976, Development problems of small countries, in L.V. Castle and F. Holmes (eds), Cooperation and Development in the Asia Pacific Region: Relations Between Large and Small Countries, Tokyo, Japan Economic Research Centre, Tokyo, 43-66.

[24] Knox, A.D., 1967, Some economic problems of small countries, in B. Benedict (ed), Problems of Smaller Territories, London, Athlone Press, London, 35-45.

[25] Kuznets, S., 1960, The economic growth of small states, in E.A.G. Robinson (ed), The Economic Consequences of the Size of Nations, London, Macmillan, London, 14-32.

[26] MacBean, A.I., and Nguyen, D.T., 1987, Commodity Problems, Prospects and Policies, London, Croom Helm.

[27] Marcy, G., 1960, How far can foreign trade and customs agreements confer upon small nations the advantages of larger nations?, in E.A.G. Robinson (ed), The Economic Consequences of the Size of Nations, London, Macmillan, 265-281.

[28] Milner, C., and Westaway, A., 1993, Country size and the medium term growth process: Some country size evidence, World Development, vol. 21, 203-212.

[29] Pant, Y.P., 1974, Problems of Development of Smaller Countries: A Study in the Problems and Prospects of the Development Process, New Delhi, Oxford University Press.

[30] Putnam, R.D., with Leonardi, R., and Nanetti, R.Y., 1993, Making Democracy Work : Civic Traditions in Modern Italy, Princetin NJ, Princeton University Press. 
[31] Roberts, R., 1994, Offshore Financial Centres, Cheltenham, Edward Elgar.

[32] Scitovsky, T., 1960, International trade and economic integration as a means of overcoming the disadvantages of a small nation, in E.A.G. Robinson (ed), The Economic Consequences of the Size of Nations, London, Macmillan, London, 282-290.

[33] Selwyn, P., 1978, Small, poor and remote: Islands at a geographical disadvantage, Institute of Development Studies Discussion Paper, Number 123, Institute of Development Studies, Brighton, University of Sussex.

[34] Streeten, P., 1993, The special problems of small countries, World Development, vol. 21, 197-202.

[35] Summers, R., and Heston, A., 1988, A new set of international comparisons of real product and price level estimates for 130 countries, Review of Income and Wealth, vol. 34, 1-25.

[36] Thomas, I., 1982, The industrialisation experience of small countries, in B. Jalan (ed), Problems and Policies in Small Economies, London, Croom Helm, London, 103-124.

[37] Tolley Publishing Co., 1993, Tolley's Tax Havens, 2nd edition, Croydon, Tolley Publishing Company.

[38] Wood, D.P.J., 1967, The small territories: Some political considerations, in B. Benedict (ed), Problems of Smaller Territories, London, Athlone Press. 


\section{Annex 1: The Variables Used in the Discriminant and Censored Regression Models}

There are eight explanatory variables for which it has been possible to develop reasonably comprehensive international statistics for the micro-states:

1. REGION, is an ordinal variable coded from 1 to 8 , which indicates the region of the world in which the micro-state or dependent territory is located. World Bank definitions of the global regions are utilised and, since the regions are ranked with the poorest region (South Asia) set as a ' 1 ' through to the richest region (North America) coded as an ' 8 '. The a priori expectation is that this variable will have a positive relationship with GNP per capita. The economic logic of this variable is that 'geography matters'. Micro-states and dependent territories may well be very open economies trading globally but regional trade links and factor market access will still be disproportionately important.

2. ISLAND, is a binary variable indicating whether the micro-state or dependent territory is an island (or archipelago) or not. The a priori expectation is for a negative relationship with GNP per capita.

3. The next five variables together represent 'industry structure' explanations of the reasons for the economic performance of different micro-states. Each of these-TOURISM, AGRIC, RESOUR, FINAN and MANFG-is a sector picked out in the micro-states literature as likely to have an important influence on economic performance. Ideally, one would wish to work with variables which identify the underlying determinants of the comparative advantages which give rise to the sectoral specialisation observed. This is, however, impossible given the data limitations. The various and disparate underlying causes of sectoral specialisation must therefore be simply taken as given. The basic 'sectoral specialisation' approach is, however, a sound one since the literature and empirical evidence on micro-states all point to the open, trading nature of these entities and their reliance on export specialisation in order to prosper. Tourism and financial services are two sectors which have proved very successful for many micro-states. The TOURISM variable is an ordinal variable indicting whether a micro-state or dependent territory has fewer (0) tourists per 1000 population than the median value (using World Tourist Organisation data for 176 countries in 1993, combined with information collected directly from the micro-states), more than the median up to the second quartile (1) or an upper quartile figure (2). TOURISM can be expected $a$ priori to have positive relationships with GNP per capita.

4. The FINAN variable is a binary variable indicating the presence or absence of a major financial services sector in a micro-state or dependent territory. This variable has relied upon an unusual amount of judgement by the authors since comprehensive data at world level simply do not exist and the presence of institutions or appropriate regulations to attract financial services does not guarantee the actual presence of a large sector. Various sources, including Tolley's Tax Havens [37] and R. Roberts, Offshore Financial Centres [31] were utilised to construct this variable.

5. MANFG attempts to pick up the influence of a strong manufacturing export sector on micro-state economic performance. Successful micro-states (e.g. Mauritius) frequently have high value added manufacturing sectors targeting key export markets. A ' 1 ' value on this binary variable indicates a greater than average share of manufacturing in GDP (using 
World Bank data and data from individual states) and a ' 0 ' value a less-than-average share of GDP in manufacturing. This variable should be positively related to GNP per capita.

6. AGRIC is included because many developing micro-states are heavily dependent upon agricultural products for export or domestic consumption. The variable is again a binary one, indicating whether or not agriculture forms a higher percentage of GDP than the world average (using World Bank data for 119 countries). Although one or two microstates produce high value agricultural products for exports, most of those dependent on the agricultural sector in the developing world are either producing large amounts of products for local consumption or are producing products such as bananas which have low prices in export markets. It is expected, therefore, that this variable will be negatively related to GNP per capita. It should be noted that correlation tests revealed that there is no significant multicollinearity between AGRIC, TOURISM and MANFG.

7. RESOUR is included in order to try to pick up those cases where a micro-state or dependent territory is fortunate enough to be endowed with a high value resource (e.g. Iceland and its fisheries and aluminium resources). Once again, a variety of sources have had to be drawn upon to construct this binary variable, including OECD data on oil and fish resources, together with specific country data for other resources (e.g. phosphates). This variable should exhibit a positive relationship with GNP per capita.

8. SOVRT is a binary variable indicating whether, using the UN definition, the entity is a sovereign micro-state (a ' 1 ' value) or a dependent territory (a ' 0 ') value. Other measures were experimented with, including number of years since independence and indicator variables identifying different colonial and former colonial powers, but none of these proved significant.

9. ODAPC is a continuous variable which measures the value of overseas development aid per capita (in $\$$ US per capita). United Nations data used. This variable should have a positive relationship with GNP per capita. 